\title{
"I" get license but "we" keep consistent: The role of self-construal in subsequent pro-environmental decision
}

\author{
Shasha Xiong ${ }^{1} \cdot$ Kui Wang $^{2} \cdot$ Lei Zhang $^{3} \cdot$ Haowen Xiao ${ }^{4}$
}

Accepted: 23 January 2022

(c) The Author(s) 2022

\begin{abstract}
How to motivate consumers to maintain environmentally responsible consumption choice rather than occasional green consumption is an important component of sustainability within modern society. Yet, past literature provides two contradictory routes for sequential pro-environmental decisions: consistency effect and licensing effect. The consistency effect builds on follows the logics of self-perception theory and implies that consumers tend to repeat their prior environmentally responsible and irresponsible decisions; the licensing effect follows a goal-based logic to highlight that past pro-environmental behaviour produces a "license" to engage in less pro-environmental behaviour. To reconcile these contradictory predictions, this study extends the existing literature by following a consistent, goal-based logic in theory and exploring self-construal as a moderator that switches from one mode of sequential pro-environmental decisions to the other. Three experimental studies affirm that self-consistency effect occurs for consumers with an accessible interdependent self-construal, but licensing effect is more pronounced for consumers with an accessible independent self-construal. In addition, the interdependent- consistency effect will be stronger and the independent-licensing effect will be weaker if consumers are reminded of high tendency of others' pro-environmental behaviour in the first decision. Together, these results shed light on the downstream consequences for consumers of pro-environmental choice, with implications for the marketing and regulation of such products.
\end{abstract}

Keywords Self-construal · Goal-regulation · Moral licensing effect $\cdot$ Pro-environmental behaviors · Goal commitment

\section{Introduction}

Environmental problems such as contaminated ecosystems and climate change are posing an increasing threat to our social sustainability (Wheeler \& Von Braun, 2013). Many environmental problems can be traced back to the accumulated choices of individuals (Nielsen, 2017). At the heart of this trend is often referred to as ethical consumerism or green consumption (White et al., 2019). Accordingly, how to motivate individuals' green consumption has been a

Kui Wang

kuiwang@jnu.edu.cn

1 Economics and Management School, Wuhan University, Wuhan, China

2 Research Institute on Brand Innovation and Development of Guangzhou, School of Management, Jinan University, Guangzhou, China

3 School of Economics and Management, Hubei University of Technology, Wuhan, China

4 Management School, Hainan University, Haikou, China hot topic during the last decade in marketing, psychology, and management literature. Researchers have traditionally focused on the direct impact factors that affect the inclination of engagement in pro-environmental actions (Antonetti \& Maklan, 2014; Gupta \& Ogden, 2009; van Valkengoed $\&$ Steg, 2019). Recently, considerable attention has been paid to the consequences of pro-environmental consumption choice for subsequent, environmentally relevant decision-making (Mullen \& Monin, 2016; Reczek et al., 2018; Thøgersen \& Crompton, 2009; Urban et al., 2019; van Valkengoed \& Steg, 2019). However, results are mixed regarding how prior pro-environmental consumption behavior affect subsequent green consumption choice.

One stream of literature demonstrates that people who have previously purchased a green product show increased inclination to make green consumption choices in future compared to control groups (van der Werff et al., 2014), which is termed the green highlighting effect. Others, conversely, show that a person's inclination to perform proenvironmental behaviour decreases after engaging in prior pro-environmental behaviour, which is termed the green 
licensing effect (van der Werff et al., 2014). These conflicting findings suggest that pro-environmental consumption choice may not have either a universally positive or negative impact on subsequent engagement in pro-environmental consumption choice, which calls for closer examination for the conditions that past pro-environmental behaviour induce consumers to strengthen (i.e., a green highlight effect) or undermine (i.e., a green licensing effect) their subsequent engagement in pro-environmental behaviour (Schwabe et al., 2018; White et al., 2019). Some recent literature has made some strides in understanding conditions of the green licensing effect by identifying some factors, such as consumers' prior environmental attitude (Gholamzadehmir et al., 2019), environmental consciousness (Garvey \& Bolton, 2017), regulatory focus (Schwabe et al., 2018), and signaling strength of past pro-environmental actions in influencing environmental self-identity (van der Werff et al., 2014).

However, there are still two issues that limit our understanding for the sequential pro-environmental consumption decision. First, the theoretical logics of the green highlighting and licensing effect are not consistent. The arguments of the green highlighting effect follow the logic of self-perception theory to propose that performing a pro-environmental behaviour enhances or activates a person's internal pro-environmental disposition and therefore increase the likelihood that the person repeats the pro-environmental behaviors in future. In short, the green highlighting arguments emphasize individuals' cognitive change in pro-environmental behaviour or self-identity after performing initial pro-environmental consumption decisions (Thøgersen \& Crompton, 2009). The arguments of the green licensing effect, however, rely on a goal logic rather than cognitive change. Specifically, the green licensing effects in sequential behavior are built on a fundamental assumption that consumers have multiple, sometimes conflicting goals which result in motive conflict for a given target behavior (Garvey \& Bolton, 2017; Mullen \& Monin, 2016). Given multiple, sometimes conflicting goals, an initial pro-environmental behavior helps individuals to "earn" credits in a metaphorical moral bank account that can be used to "buy" forgiveness/license for their nonsustainable behaviors that are targeted at other goals rather the environmental protection goal (Thøgersen \& Crompton, 2009). These separate and different logics for green licensing and highlighting effect are key source of confusion on the consequence of initial pro-environmental consumption decisions on subsequent pro-environmental behaviors. Thus, we need to use a unified theoretical account to simultaneously explain the green licensing and green highlighting phenomena.

Second, cross-cultural differences are the main factors to help us understand sequential pro-environmental consumption decision, and some researchers found the crosscultural differences in the effect sizes of moral licensing
(Simbrunner \& Schlegelmilch, 2017), but we still do not know which cultural factors determines this cross-cultural difference. Recently, Simbrunner and Schlegelmilch (2017) made some strides in understanding sequential moral decision making through a meta-analysis of the moral licensing effect. They found that moral licensing effect is stronger in North America and Western Europe compared to SouthEast Asians. Furthermore, they found for South-East Asian, displaying moral behavior increases the likelihood of acting in a moral way subsequently. However, we still cannot understand why the effect sizes of moral licensing in Asian is lower, compared to North America and Western Europe. Researchers do not take a further step to explain the reasons for the difference between South-East and North America or Western Europe.

In this study, we propose two solutions for above research gaps. First, we use a consistent and goal-related logic to examine the impact of initial pro-environmental consumption decisions on subsequent pro-environmental behaviors by applying the goal-regulation theoretical framework (Fishbach \& Dhar, 2005; Fishbach et al., 2009; Shaddy et al., 2021). The goal-regulation theorical framework proposed by Fishbach and Dhar (2005) assumes that individuals take actions according to the goals they hold and individual pursue multiple goals. According to the goal-regulation theoretical framework, whether green licensing or green spillover emerges depends on whether past pro-environmental actions are represented as either progress toward the goal of being an environmentally-friendly person. Therefore, we contribute to the extant literature by providing a coherent goal-related underlying processes that initial pro-environmental consumption affect subsequent pro-environmental behaviour.

Second, we focus on a cultural factor that differ in SouthEast Asia and North America or Western Europe: self-construal. Self-construal refers to how people view themselves to be linked (or not) with others and the social environment (Markus \& Kitayama, 1991). Considerable research in cultural psychology has focused the difference between independent self-construal and interdependent self-construal, highlighting the distinction between independent self and interdependent self captures a key aspect of cultural difference between South-East and North America or Western Europe (Aaker \& Lee, 2001). Specially, Western cultures tend to foster an independent self-construal, whereas Eastern cultures tend to foster an interdependent self-construal (Markus \& Kitayama, 1991). Although these two self-construals are chronically nurtured in different cultures, past research has widely demonstrated that a different self-construal can also be made temporarily accessible and manipulated through referencing tasks and situational contexts, and primes (Ng \& Houston, 2006). For example, some research manipulated self-construal by selecting a group of subjects from South-East Asia background (including China and 
Japan) as the interdependent self-construal group and a group of subjects from North American cultural background (e.g.,Ng \& Houston, 2006; Trafimow et al., 1991; Yang et al., 2015). The salience of each type of self-construal can also be experimentally manipulated. For example, some research primes self-construal (independent vs. interdependent) through visual imagery and ad copy (e.g., Aaker \& Lee, 2001; Hamilton \& Biehal, 2005; Lee \& Pounders, 2019; Ng $\&$ Houston, 2006), while others manipulate self-construal through story scene immersion, such as a famous story about Sostoras (Mandel, 2003; Trafimow et al., 1991; Ybarra \& Trafimow, 1998) and a widely adopted scenario about a trip to the city (e.g., Brewer \& Gardner, 1996; Hong \& Chang, 2015; Krishna et al., 2008).

In the present research, we follow the goal-regulation theoretical framework to predict that interdependent selfconstrual consumers consider previous pro-environmental behavior as goal commitment, which renews their efforts toward pro-environmental goal pursuit, indicating consistency effect (Fishbach et al., 2009; Susewind \& Hoelzl, 2014). In contrast, independent self-construal consumers consider pervious pro-environmental behavior as goal progress, which decrease their efforts on pro-environmental goal pursuit, showing licensing effect (Fishbach \& Dhar, 2005; Shaddy et al., 2021). In addition, when consumers are informed others' widespread participation in initial proenvironmental behavior, the self-consistency effect will be stronger, but the self-licensing effect will be weaker. Thus, we extend Simbrunner and Schlegelmilch's (2017) findings and contribute to our understanding of when the green highlighting effect or the green licensing effect occurs. Using the procedure of Garvey and Bolton (2017) to manipulate pro-environmental behavior and the manipulation of selfconstrual from $\mathrm{Ng}$ and Houston (2006), we employed three experiments to support our hypotheses.

\section{Theoretical Background and Hypotheses Development}

\section{The Highlighting and Licensing Effects of Past Pro-Environmental Behavior}

How does prior pro-environmental consumer behaviors affect a consumer's "next" environmentally responsible behavior? Extant research is remarkably divided into two conflict views summarily denoted as the green highlighting effect and the green licensing effect (Garvey \& Bolton, 2017; Urban et al., 2019; van der Werff et al., 2014).

The researchers that support the green highlighting effect argue that initial pro-environmental consumer behaviors result in more subsequent pro-environmental behavior compared to participants without prior pro-environmental consumption behavior (Cornelissen et al., 2008; van der Werff et al., 2014). For example, researchers have shown consumers buy more organic food after bringing their own shopping bags (Karmarkar and Bollinger, 2015), have more altruistic behaviors after priming with green consumption (Mazar and Zhong, 2010), and increase sustainable actions by framing previous common environmental behaviors as environmental (Cornelissen et al., 2008). The argument of the green highlighting effect generally follows the logics of self-perception theory which suggests that people use their own behavior as cues to draw conclusions about themselves (Bem, 1972). Specially, prior pro-environmental consumption behavior can increase actors' environmental self-identity which then enhances the motivation to engage in proenvironmental consumer choices in future (van der Werff et al., 2014). In contrast, inconsistencies in our beliefs, attitudes, and behaviors are psychologically distressing called as "cognitive dissonance" that people are motivated to avoid it (Festinger, 1957). The desire to avoid cognitive dissonance is assumed to create a drive to behave consistently, which results in a positive effect of initial pro-environmental acts on subsequent pro-environmental behaviors (Thøgersen, 2004).

Conversely, researchers who support the green licensing effect suggest that initial pro-environmental consumer behaviors result in less subsequent pro-environmental behavior (Garvey \& Bolton, 2017; Schwabe et al., 2018; Urban et al., 2019). For example, Karmarkar and Bollinger (2015) found that participants who brought reusable shopping bags purchased more indulgent foods. Similarly, Noblet and McCoy (2017) found individuals who participated in past sustainable energy behavior were less to support energy renewable policy. Generally, the explanations for the green licensing effect emphasize individuals' multiple, sometimes conflicting goals which results in trade-offs between prosocial and self-interest goals (Mullen \& Monin, 2016). As Mullen and Monin (2016) stated, "for licensing effects to occur, there must be a conflict of motives in the target behavior (e.g., between self-interest and doing the 'right' thing) that manifests as temptation or suspicion" (p.367). An initial pro-environmental behavior helps individuals to "earn" credits in a metaphorical moral bank account that can be used to "buy" forgiveness/license for their non-sustainable behaviors which are driven by other goals rather than prosocial goals (Mullen \& Monin, 2016). Or, performing an initial pro-environmental act provides a lens through which subsequent non-sustainable behaviors are less likely to be interpreted as immoral (Mullen \& Monin, 2016).

Taken together, previous literature show both the green licensing effect and green highlighting effect may occur after initial pro-environmental behavior. More importantly, the green licensing effect and green highlighting effect are two separate theses, because their logics—-self-perception versus 
conflicting goals - are different. Recently, some researchers have attempt to answer this question and identified some several moderators that determine whether the green licensing effect or green highlighting effect occurs after engaging in initial pro-environmental behaviors, such as prior environmental attitude (Garvey \& Bolton, 2017), signaling strength of past pro-environmental actions in influencing environmental self-identity (van der Werff et al., 2014), and consumers' regulatory focus (Schwabe et al., 2018). Although these studies contribute to our understanding for the impact of pro-environmental consumption behaviors on subsequent environmentally responsible behavior, these studies still use self-perception logic to explain the green highlighting effect and use conflicting goals to explain the green licensing effect. There is still not a consistent and unified theoretical logic that can be employed to predict when the green highlighting effect or green licensing effect occurs.

In this paper, we use a consistent logic to make theoretical predictions by applying the goal-regulation theoretical framework (Fishbach \& Dhar, 2005; Fishbach et al., 2009; Shaddy et al., 2021). Furthermore, we identify consumer's self-construal as a new moderation to predict when the green highlighting effect and green licensing effect will occur after performing a pro-environmental consumer behaviour.

\section{The Goal-Regulation Theoretical Framework and Sequential Pro-Environmental Decision Making}

The goal-regulation theoretical framework can be a valuable prospective on explanation for when the green highlighting and licensing effect occur in the context of pro-environmental behaviors. Previous researches suggest that people pursue multiple self-relevant goals simultaneously, such as environmental protection and self-convenience (Fishbach et al., 2009), enjoying delicious food and wanting a slender figure (Fishbach \& Dhar, 2005), and these goals direct their sequential behaviors. Therefore, no matter what kind of behavior an individual performs (consistent or inconsistent pro-environmental decision making), the motivation of the behavior may be the result of competition between different goals.

According to the goal-regulation theoretical framework, when individuals hold multiple activated goals and these goals are not synergistic, they need to make a choice between maintaining the pursuit of a single goal by a course of subsequent actions that are consistent and alternating the pursuit of these goals by balancing the progress of these goals (Fishbach \& Dhar, 2005). The goal-regulation theoretical framework propose that the same goal-related actions can be represented in terms of either progress toward a desirable end state or commitment to this end state, which then determines either balance among goals toward which they experience progress, or highlighting goals to which they feel committed (Fishbach et al., 2009). The different perspective in framing the initial pursuit of a goal has important implications for subsequent goal-related actions. Specially, when individuals interpret their previous goal-related behavior as a signal of progress towards the goal, they will have a sense of goal achievement and fulfilment which then undermines the motivation to choose goalcongruent actions and balance between this goal and others (Fishbach et al., 2009). This argument is built on the findings that when people have multiple activated goals, the choice of actions that pursue one goal but completely neglect another is likely to be more aversive than when only a single goal is salient (Dhar \& Simonson, 1999; Fishbach \& Dhar, 2005). Consequently, they will be more likely to reduce goal-congruent actions and increase actions aimed at achieving other conflict goals when their previous goal-related behaviors are interpreted as a signal of progress on the focal goal (Fishbach et al., 2009). In contrast, when individuals represent pursuing a goal as a signal of their commitment to the goal, their past goal-related behaviors highlight this goal after successful goalseeking behavior. That is, when people represent previous goal actions as commitment to the focal goal, they will highlight that goal and prioritize the goal by engaging in goal congruent behavior in subsequent situations after successful pursuit (Fishbach \& Dhar, 2005; Fishbach et al., 2009)

In summary, according to the goal-regulation theoretical framework, the green highlighting effect occurs in sequential pro-environmental behavior paradigms when people represent initial pro-environmental behavior as signaling commitment to the environmental-friendly goal. In other words, an initial pro-environmental consumption will enhance subsequent pro-environmental behavior when this initial pro-environmental consumption is represented as commitment to the environmental-friendly goal. In contrast, the green licensing effect occurs in sequential pro-environmental behavior paradigms when people represent initial pro-environmental behavior as goal satiation towards the environmentalfriendly goal. In other words, an initial pro-environmental consumption will undermine subsequent pro-environmental behavior when this initial pro-environmental consumption is represented as goal satiation towards the environmentalfriendly goal. Despite these intriguing predictions, we still poorly understand when and why a same moral behavior is represented as goal commitment or goal progress, which then determines whether moral consistency or licensing effect will emerge. To account for it, we next focus on a theoretically and substantively important factor: Self-construal.

\section{Resolving the Discrepancy: The Moderating Role of Self-Construal}

Self-construal refers to the way people view themselves and make meaning about the self in relation to others (Lee \& Pounders, 2019). Self-construal can be classified into 
independent and interdependent self-construal (Markus and Kitayama, 1991). Independent self-construal prioritizes the self over others and strive toward being unique, different, and separate from others (Aaker \& Lee, 2001). In contrast, interdependent self-construal tend to define themselves by their social roles and relationships with others, and prioritizes social groups and goals over one's own personal wishes or desires (Markus and Kitayama, 1991). By their very nature, in pro-environmental behavior situations, such as recycling, purchasing green products, people often have to make a trade-off between the welfare of others (e.g., paying a higher price for sustainable products to benefit the environment and social) and their own self-interests (e.g., lower cost of conventional product) (Aquino et al., 2009). As White et al. (2019) stated, "views of sustainable consumer behaviors often imply putting aside wants that are relevant to the self and prioritizing and valuing entities that are outside of the self (e.g., other people, the environment, future generations, etc.)"(p.32).

Many researchers have suggested that the self-construal type will moderate the impact of past pro-environmental behavior on subsequent pro-environmental behavior. Specifically, interdependent individuals place more weight on stability and continuity of social ties (Markus and Kitayama, 1991), and tend to engage in more stability- and harmonyfostering activities (Yang et al., 2015), whereas interdependent individuals emphasize on distinguishing from others and engage in more advancement-related activities (Yang et al., 2015). Given the desire to succeed relative to others, people with independent self-construal pay more attention to progress from a status quo to a new, better state than interdependent individuals (Aaker \& Lee, 2001). As a result, people with independent self-construal will be more likely to represent their prior pro-environmental behavior as progress toward the goal of developing a self-image of being a moral person, which licenses their less pro-environmental decisions and a greater focus on one's self-interest in sequential consumption decision. In contrast, people with interdependent assign more weight to maintain the social norm and their status, they are inclined to link their past behavior with their status quo and social norm (Yang et al., 2015). Since their prior pro-environmental behavior constitute the basis that others evaluate them, people with interdependent self-construal are more likely to represent their prior pro-environmental behavior as commitment, so prior proenvironmental behaviors lead to more pro-environmental behavior in subsequent consumption decisions.

The reasoning receives some support from prior literature. For example, one meta-analytical study from Simbrunner and Schlegelmilch (2017) found that moral licensing effect is applicable in the context of North America or Europe and consistency effect is applicable in the context of South-East. Usually, people from America or Europe tends to be more independent and less interdependent selfconstrual than Asians (Markus and Kitayama, 1991), which imply the association between independent-license effect and interdependent-consistency effect. In addition, Schwabe et al. (2018) found that promotion-focused individuals tended to have licensing effect whereas prevention-focused individuals tended to have consistency effect. A great deal of self-construal research has shown that independent individuals tend to be promotion focus, while interdependent individuals tend to be prevention focus (Aaker \& Lee, 2001). Given the relationship between regulatory focus and selfconstrual, the findings from Schwabe et al. (2018) also support our predictions.

Based on previous studies, we predict in the context of sequential pro-environmental consumption behavior, moral licensing effect will be more likely to emerge among individuals with independent self, while moral consistency will more likely to emerge among individuals with interdependent self.

H1. Among individuals with independent self, (a) prior pro-environmental consumption decisions positively affect perceived progress toward the environmentalfriendly goal, (b) and then lead to less pro-environmental behavior in subsequent consumption decisions.

H2. Among individuals with interdependent self, (a) prior pro-environmental consumption decisions positively affect perceived commitment to the environmentalfriendly goal, (b) and then lead to more pro-environmental behavior in subsequent consumption decisions.

\section{The Role of Others' Behavior}

Given the potential negative consequences of licensing effect and positive consequence of consistency effect, a natural question arises concerning how to facilitate people to take the goal commitment perspective rather than the goal progress perspective to interpret their past pro-environmental practice. In this paper, we focus on the role of social information. In practice, people pursue goals in social environments rather than in vacuum. As social beings, people often seek for information from similar others to adjust their goal pursuit motivation and behavior (Huang et al., 2015; Huang et al., 2017a, b). People often compare with social reference group to evaluate the value of action and their position in the process of goal pursuit (Festinger, 1954). On the one hand, information on others' pro-environmental behavior constitute the most meaningful benchmarks and thus serve as the most valuable social referent which provide a referent point to infer their progress (Huang, 2018). Besides, information on others' pro-environmental behavior also constitutes a social norm. Many research suggested that the more people 
adopt an action, the more "taken for granted" this action will be (Steinmetz et al., 2016).

We predict that others' prior pro-environmental behavior should moderate the effects of initial pro-environmental behaviors on subsequent sustainable consumption decisions among those whose independent self-construal is activated. Because of the importance of being distinct from others and individual advancement, individuals with independent selfconstrual infer their prior pro-environmental behavior as less progress towards the goal of developing a self-image of being a moral person when they are informed of information that many people also adopt their prior pro-environmental behavior. In other words, information about others' prior pro-environmental behavior provides a social referent point to assess their progress. For individuals with independent self, the information that a great number of people also adopt their prior pro-environmental behavior signals that their proenvironmental behavior cannot distinguished themselves from others. Therefore, we predict the licensing effect of prior pro-environmental behavior will be weaker for individuals with an accessible independent self-construal when information on others' widespread participation in initial pro-environmental behavior, as compared with when no information is provided or information on low social participation in initial pro-environmental behavior.

H3. When information on others' widespread participation in initial pro-environmental behavior is provided,as compared with when information on low social participation in initial pro-environmental behavior or no information is provided, the negative relationship between prior pro-environmental consumption decisions and pro-environmental behavior in subsequent consumption decisions for individuals with an accessible independent self-construal will be weaker.

People with independent self-construal, however tends to define themselves by their social roles and relationships with others (Aaker \& Lee, 2001) and place greater value on goals of social cohesion, maintaining harmonious relationship(s) with close others, and conforming to social norms (Heine et al., 1999). Because of the importance of connection with others and belonging to an in-group (Smith and Louis 2008), people with a interdependent self-construal focus on group goals and the standards held by others (Aaker \& Lee, 2001; Cross et al., 2010). It is reasonable for individuals with interdependent self-construal to infer that pro-environmental goal is pursued by others when they are informed that their initial pro-environmental behaviors are also adopted by many people. Given their desire to connectedness, conformity, and group harmony of consumer with interdependent selfconstrual (Aaker \& Lee, 2001; Hamilton \& Biehal, 2005), others' pro-environmental behaviors inform them that their prior pro-environmental behaviors are associated with social norm which increases the perceived value of pro-environmental goal. Therefore, we expect can others' prior pro-environmental behaviors promote individuals with interdependent self-construal to represent their prior pro-environmental behaviors as commitment to pro-environmental goal, and thus enhance the positive relationship between prior proenvironmental consumption decisions and pro-environmental behavior in subsequent consumption decisions.

H4. When information on others' widespread participation in initial pro-environmental behavior is provided,as compared with when information on low social participation in initial pro-environmental behavior or no information is provided, the positive relationship between prior pro-environmental consumption decisions and pro-environmental behavior in subsequent consumption decisions for individuals with an accessible interdependent selfconstrual will be stronger.

\section{Empirical Overview}

We designed three studies to test the hypotheses. In study 1 , in a test of hypothesis 1 and 2, we examined whether individuals with a situationally induced interdependent selfconstrual repeated their past pro-environmental consumption decisions after engaging into an initial sustainable consumption behavior, but individuals with a situationally induced independent self-construal regulated pro-environmental behavior through licensing. Study 2 similarly examined the two discrete processes (goal satiation and pro-environmental commitment) underlying this interaction. Finally, to assess the moderate role of others' pro-environmental behavior, Study 3 reminded participants others' pro-environmental behavior in the first decision and examined whether others' participation in pro-environmental behavior can weaken the licensing effect among independent participants and enhance the self-consistency effect among interdependent participants - in a test of $\mathrm{H} 3$ and $\mathrm{H} 4$.

\section{Study 1: Sequential Sustainable Decisions and the Moderating Role of Self-Construal}

\section{Method}

\section{Participants and Design}

The primary purpose of Study 1 is to test the moderating role of self-construal in the relationship between previous sustainable consumption decision and subsequent pro-environmental behaviors. The study employed a 2 (first decision: green-product choice vs. conventional) $\times 2$ (self-construal: 
independent vs. interdependent) between-subjects design. 122 students ( 63 females, 59 males, $M_{\text {age }}=20.4, S D=1.89$ ) from a University of Guangzhou, in China volunteered for participation in this study.

\section{Materials and Procedure}

We first manipulate the self-construal (independent vs. Interdependent self) of all participants by using external stimulus. Although preliminary research shows cultural background heavily influence individual's self-construction (Markus and Kitayama, 1991), later studies have shown that these two self-construal can coexist within one person and temporarily accessible through referencing tasks (Aaker \& Lee, 2001). In our study, we experimentally manipulated self-construal through the procedure of Hamilton and Biehal (2005)

This manipulation has also been applied effectively in many other studies (Ng \& Houston, 2006; Zhang \& Shrum, 2008; Zhu \& Meyers-Levy, 2009). Specially, we told the subjects that the study was designed to obtain a measure of happiness. Then, half of the participants saw a fictitious advertisement showing a person enjoying quiet time alone on the beach with a caption, and read "Remember, enjoying your life is what it is really all about" (independent prime). The other half of participants saw an advertisement showing a group of friends chasing, laughing, and romping on the beach together accompanied by the caption "Remember, enjoying affection between family members or friendship among friends is what it is really all about" (interdependent)". After reading, participants were given five minutes to write down their thoughts about this advertisement, a task intended to reinforce and strengthen the prime.

In the second portion of the experiment, we used Garvey and Bolton (2017) procedure to manipulate initial greenproduct choice. We asked people to read: "Imagine that you are at the supermarket and stocking up on kitchen essentials. For cleaning and cooking purposes, you decided to choose disposable paper towels [with Eco-Nurture additives]'. Participants in the sustainable experimental condition selected disposable paper towels with Eco-Nurture additives, whereas participants in the conventional condition selected disposable paper towels (see Fig. 1).

Next, we asked them to continue to imagine: "you continue to shop at the same store for some other household essentials. How likely are you to purchase the following products?" Participants then were presented with choice pairs that represented sustainable product and conventional product. As with Garvey and Bolton (2017), choice pairs involved six household items: dish detergent, batteries, light bulbs, cooking oil, hand soap, and laundry detergent. Table 1 describes these six the choice pairs. After viewing each option, participants were asked to report their purchase intention for each option. The response was rated using a 7-point scale from endpoint 1 (definitely did not purchase) to 7 (very likely). A relative preference index for sustainable product was calculated by averaging intention ratings for the six sustainable product options and the six conventional product options (reverse-coded). Next, participants answered questions to check the manipulations. Participants were asked to complete the self-construal scale developed by Singelis (1994) to confirm whether the manipulation was successful. The self-construal scale consists of 24 items that assess people's chronic self-construal, of which includes 12 items for each construct. As a manipulation check for the eco-product manipulations, participants were asked to rate environmental responsibility of all options (including paper towels in manipulation task and six household items in the final task of purchasing choice).

Finally, participants completed a manipulation check and background information. (e.g., gender, age). None of them expressed any suspicion regarding the self-construal manipulation.

\section{Results}

\section{Manipulation Checks}

Supporting the manipulation of the sustainable product consumption, ANOVA revealed that disposable paper towels with Eco-Nurture additives were perceived as more environmental responsibility than conventional disposable paper towels $\left(\mathrm{M}_{\text {green-product }}=5.365, \mathrm{M}_{\text {control }}=2.345 ; \mathrm{F}(1,118)\right.$ $=141.7, p<.001)$. To test the manipulation validity of the choice pair options, we conducted a series of t-tests. The results showed that the pro-environmental ratings were greater for the sustainable product options than for the conventional options (p's < .05). Table 1 contains descriptive means for each choice option and corresponding test statistics for the choice pairs. To check if self-construal was successfully manipulated, 2 (self-construal: independent vs. interdependent) $\times 2$ (focus: self or others) ANOVA showed that interdependent self-priming group thought more about their family or friends than themselves $(M=4.85)$ whereas independent self-priming group thought more on themselves $(\mathrm{M}=2.36 ; \mathrm{F}(1,118)=127.99, p<.001)$, which confirmed that this manipulation was successful.

\section{Tests of Hypotheses}

To test hypothesis 1 and 2, we conducted a two-way ANOVA with initial product choice (green-product choice vs. control) and self-construal as the independent variable, and relative preference for sustainable products as the dependent variable. The results showed that the main effects of initial green-product choice $(\mathrm{F}(1,118)=.06$, $p>.05)$ and self-construal $(\mathrm{F}(1,118)=.08, p>.05)$ 
Fig. 1 a Product presentation, control condition (Study 1). b Product presentation, sustainable product condition (Study 1)
想象你正在选超市，采购㕌房必需品 ( Imagine that you are at the supermarket and stocking up on kitchen essentials.) 为了厨房清洁和亨饪目的，你决定选择如下这款一次性纸巾。

(For cleaning and cooking purposes, you decided to choose Disposable Paper Towels)

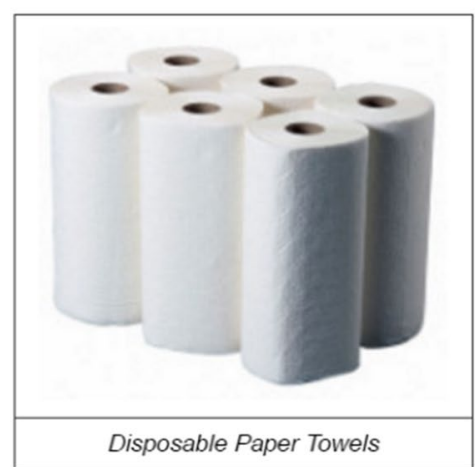

产品描述：用最小的付出，体验最佳的便利。

"Experience convenience with a minimum of effort."

\section{a}

想象你正在括超市，采购厨房必须品 (Image that you are at the supermarket and stocking up on kitchen essentials) 为了清洁和毫洎目的，你觉得选择带有环保成分的一次性纸巾

For cleaning and cooking purposes, you decided to choose Disposable Paper Towels with Eco-Nurture Additives.

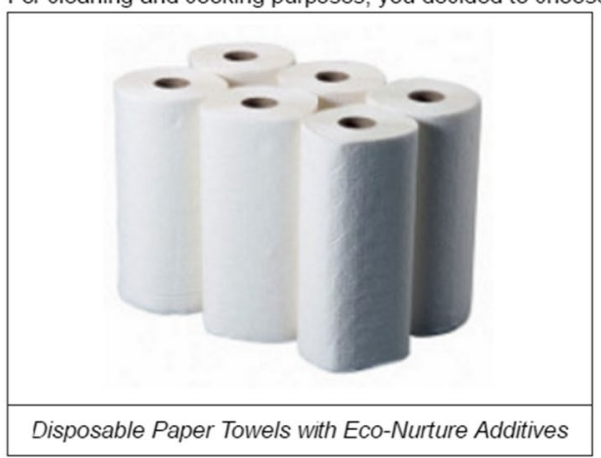

产品描述：该纸巾使用便捷，且有利于环境保护。这些纸巾采用可降解的材料制作，并含有可做土地肥料的营养成分。

"Have convenience and help out the environment. These bio-degradable towels actually contain vital nutrients that nurture the earth."

b

Table 1 Purchase index options

\begin{tabular}{llll}
\hline Product & Sustainable Product Options & Conventional Product Options & \\
\hline & Description \& Rating & Description \& Rating & Paired $t$ Test \\
Batteries & Rechargeable & Disposable & $\mathrm{t}=2.68, p<0.01$ \\
Light Bulbs & Low energy consumption & Brighter lights & $\mathrm{t}=3.25, p<0.01$ \\
Cooking Oil & Recyclable glass bottle design & Convenient plastic bottle design & $\mathrm{t}=2.91, p<0.01$ \\
Hand Soap & Sanitizes with fruit extract & Chemicals kill hand germs dead & $\mathrm{t}=1.95, p<0.1$ \\
Dish Detergent & Less suds, longer washes & More suds to kill bacteria & $\mathrm{t}=2.00, p<0.05$ \\
Laundry Detergent & Now without bleach & Now with bleach & $\mathrm{t}=1.98, p<0.05$ \\
\hline
\end{tabular}

on relative preference for sustainable products were not significant. However, the predicted two-way interaction between initial green-product choice and self-construal was significant $(\mathrm{F}(2,118)=28.05, p<.001)$. To deepen our understanding for this interaction, we separately analyzed the impact of the initial eco-product choice on relative preference for sustainable products among independent and interdependent participants, as shown in
Fig. 2. Independent self-construal group exhibited the licensing effect: relative preference for sustainable products was lower among participants who chosen a greenproduct in their first decision $(\mathrm{F}(1,58)=18.83, p<.001$; $\left.\mathrm{M}_{\text {green-product }}=2.65, \mathrm{M}_{\text {control }}=4.13, p<.05\right)$, which supports the H1b. On the contrary, interdependent selfpriming group exhibited self-consistency effect: relative preference for sustainable products was higher among 
participants who chosen an eco-product in their first decision $\left(\mathrm{F}(1,60)=12.70, p<.001 ; \mathrm{M}_{\text {green-product }}=5.24, \mathrm{M}\right.$ control $=4.10, p<.05)$, which supports H2b.

\section{Discussion}

The results of study 1 provide evidence for our prediction that the effect of initial sustainable purchase on subsequent sustainable purchase is contingent on individual self-construal. Specifically, moral licensing effect will be more likely to emerge among individuals with independent self, while moral consistency will more likely to emerge among individuals with interdependent self. In study 1, we manipulated the initial sustainable product consumption by randomly assigning participants into sustainable experiment group and conventional group. In Studies 2, we tried to replicate study 1 by using a different sample and different operationalization of pro-environmental behavior. Furthermore, we let participation do actual behavioral decision to provide stronger tests of our hypothesis. Study 2 also tried to provide further evidence for the underlying psychological mechanisms that underlie the interaction between initial sustainable choice and self-construal. Specifically, we expect a) a mediation via goal satiation among individuals with independent self-construal (leading to licensing effect) and b) a mediation via commitment to the environmental-friendly goal among individuals with interdependent self-construal (leading to self-consistency effect).

\section{Study 2: Psychological Mechanisms that Drive the Consistency and Licensing Effects}

\section{Method}

\section{Participants and Design}

By manipulating the environmental responsibility of the first decision and individuals' self-construal, we used a 2(first

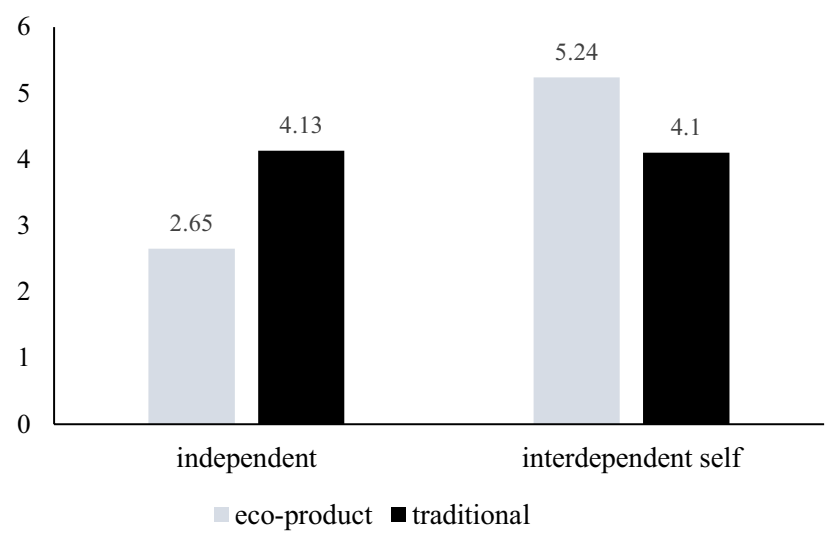

Fig. 2 Graphical representation of Study 1 results decision: green-product choice vs. conventional) $\times 2$ (selfconstrual: independent vs. interdependent self) betweensubjects design. Two hundred and thirty-one Chinese participants ( 95 males and 136 females, $M_{\text {Age }}=29.89, \mathrm{SD}_{\text {Age }}$ $=10.35$ ) from an online panel voluntarily participated in the study 2 in exchange for $10 \mathrm{RMB}$. In order to ensure the high quality of the data, we designed two attention check items (e.g., "What were the product you seen?") to exclude participants who did not pay attention to our materials. Twenty-one participants were excluded from our sample because they failed at least one of the two attention check. Therefore, our final sample only included 211 participants.

\section{Materials and Procedure}

Participants were told that the purpose of this experiment is to investigate how people view some existing brands and they were taking part in three studies. In the first study, participants completed the same self-construal priming task used in study 1 . As ostensibly part of a second study, participants were asked to complete an initial consumption decision. Specially, participants were asked to imagine themselves in a shopping scenario and make their initial choice between two products at the same price: a green product vs a conventional product. More precisely, they read: "Imagine that you are shopping for some household necessities. You are first looking for something to clean the kitchen. Then, you find two types of towels with the same price on the goods shelf that satisfy your wants:" We used two product samples: paper towel options and cotton towel options. Then participants were presented with the two types of paper towel options and two types of cotton towel options. Participants then were asked to freely choose one or the other option.

Once participants made a choice, they received information about only one of the samples to move into a third study. For the control group, they were asked to read "Please choose one of the two products and then put your choice into your shopping cart." For the sustainable product consumption group, they were asked to read "Please choose one of the two products and then put your choice into your shopping cart. Please look at the package of the product, and then there is a sentence that will catch your attention: These towels are made of biodegradable materials and therefore help to protect the environment."

We told the subjects that they were shopping at the store for some household essentials. As with the procedure of study 1, participants indicated their purchase intentions toward choice options (the same used in Study 1). A relative preference index for sustainable product was calculated by averaging purchase preference for six sustainable product and six conventional products (Reverse coding). 
Participants then were asked to respond to psychological process measures including goal satiation and commitment to the environmental-friendly goal. To measure perceived goal satiation, we adapted the measure method from Etkin and Ratner (2012) to ask: "Please think carefully about your own environmental goals. If you buy this product, to what extent will your personal environmental goals be missed, met or exceeded?" We used a 7-point scale for the measurement, in which both ends of the scale indicated that my personal environmental goals were not met/exceeded. As a measure of commitment to the environmental-friendly goal, we adapted the measure method from Huang et al. (2017a, b) to ask participants: "Think about your previous towel product selection. 'How much value do you think there is in taking action to protect the environment?' [9-point scale from endpoint 1 (no value at all) to 9 (very high value)]". Finally, participants completed a serial of manipulation checks, background information (e.g., gender, age), and quality check items.

\section{Results}

\section{Manipulation Checks}

In line with our expectations, for green product group, their rating on environmental responsibility for previous product selection was higher than those in the conventional condition ( $\mathrm{M}_{\text {sustainable }}=5.34, \mathrm{M}_{\text {Non-sustainable }}=4.16 ; \mathrm{F}(1,207)$ $=58.46, p<.01)$. We adapted from Aaker and Lee (2001) to test the independent self-construct subjects were more concerned with themselves or less concerned with others. As we expected, as opposed to the interdependent self-construction group $(\mathrm{M}=3.71)$, independent self-construction group were more concerned with themselves $(\mathrm{M}=4.78 ; \mathrm{F}(1,207)$ $=11.15, p<.01)$, whereas interdependent self-construction group were more concerned with their family and friends than independent self-construction group $\left(\mathrm{M}_{\text {independent }}=\right.$ 3.42 vs $\left._{\text {interdependent }}=2.60 ; \mathrm{F}(1,207)=8.98, p<.01\right)$.

\section{Hypotheses Testing}

The results of one-way ANOVA showed that there was no significant main effect of initial sustainable product choice on relative preference for sustainable products $(\mathrm{F}(1$, $209)=2.20, p=0.11)$. In order to test $\mathrm{H} 1 \mathrm{~b}$ and $\mathrm{H} 2 \mathrm{~b}$, we conducted a 2 (goal framing: intrinsic vs. extrinsic) $\times 2$ (selfconstrual: independent vs. interdependent) ANOVA, and the dependent variable was relative preference for sustainable products. The results showed significant interaction effect $(\mathrm{F}(1,207)=6.34, p<.05)$. Specially, interdependent selfconstruction group indicated higher relative preference for sustainable products when initial choice was a green-product
$(\mathrm{M}=4.64)$ than traditional product $(\mathrm{M}=3.74, p=.04)$. On the contrary, independent self-construction group had lower relative preference for sustainable products if their initial choice was a green product than if initial choice was traditional product $\left(\mathrm{M}_{\text {green }}=3.57, \mathrm{M}_{\text {traditional }}=4.19, p=\right.$ $.07)$. Thus, $\mathrm{H} 1 \mathrm{~b}$ and $\mathrm{H} 2 \mathrm{~b}$ were supported.

Then we used the PROCESS SPSS Macro (Hayes, 2017), Model 8) to test the moderated mediation model in which we defined subsequent relative preference of sustainable products as the dependent variable, perceived goal satiation and commitment to the environmental-friendly goal as simultaneous mediators, self-construal as the moderator $(0$ $=$ interdependent, $1=$ independent $)$, and the initial sustainable product choice $(0=$ traditional, $1=$ sustainable $)$ as the independent variable. The results supported our predictions (see Fig. 3).

As shown in Fig. 3a, the perceived goal satiation reduced subsequent preference for sustainable products $(b=-0.36, \mathrm{t}$ $(211)=2.99, p<0.01)$; commitment to the environmentalfriendly goal enhanced subsequent preference for sustainable products $(\mathrm{b}=0.41, \mathrm{t}(211)=2.02, p<0.05)$. For the interdependent situational prime group, the indirect effect of initial sustainable consumption on subsequent preference for sustainable products (via perceived goal satiation) was not significant, while the indirect effect of initial sustainable consumption on subsequent sustainable product choice (via commitment to environmental goal) was positive and significant $(b=0.18,95 \%$ [LLCI, ULCI $)]=[0.06,1.08])$. That is, commitment to environmental goal mediated the selfconsistency effect for individuals with an interdependent self. Therefore, H3 was supported. On the contrary, for the independent situational prime group, as shown in Fig. 3b, the indirect effect of initial sustainable consumption on subsequent preference for sustainable products (via perceived goal satiation) was negative and significant ( $b=-0.64 ; 95 \%$ $[\mathrm{LLCI}, \mathrm{ULCI})]=[-1.35,-0.23])$, while the indirect effect via commitment to environmental goal was not significant $(b=$ $0.12 ; 95 \%$ [LLCI, ULCI)] $=[-0.03,0.99])$. That is, perceived goal satiation mediated the licensing effect for individuals with independent self-construal.

\section{Discussion of Study 2}

Study 2 lend further support to the robustness of our Study 1 findings. We showed that licensing effect would be more likely to emerge among individuals with independent self, while consistency effect would be more likely to occur among individuals with interdependent self. Furthermore, the self-construal determined whether individuals took a goal commitment perspective or a goal progress perspective to represent their initial pro-environmental behaviors. Individuals with independent self-construal take a goal progress perspective, represent their initial pro-environmental 
Fig. 3 a Indirect effects of initial sustainable product choice in the interdependent situational prime condition. $\mathbf{b}$ Indirect effects of initial sustainable product choice in the independent situational prime condition
For participants the interdependent situational

Indirect effect via commitment to environmental goal $=0.18^{*}, 95 \% \mathrm{CI}=(0.06,1.08)$

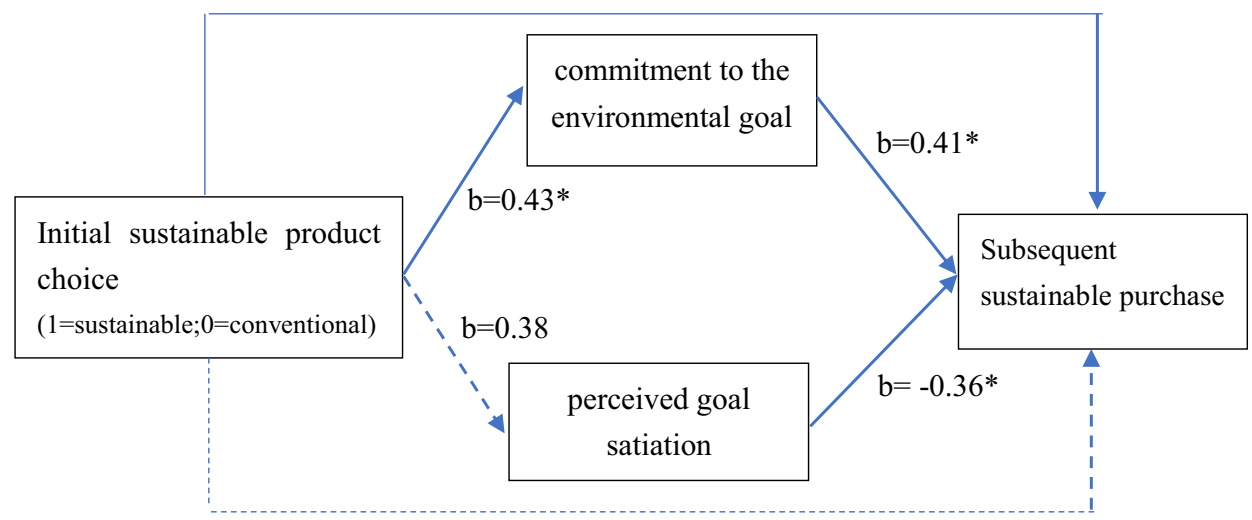

a Indirect effect via perceived goal satiation $=-0.14 *, 95 \% \mathrm{CI}=(-0.59,0.23)$

For participants the independent situational prime Indirect effect via commitment to environmental goal $=0.12,95 \% \mathrm{CI}=(-0.03,0.99)$

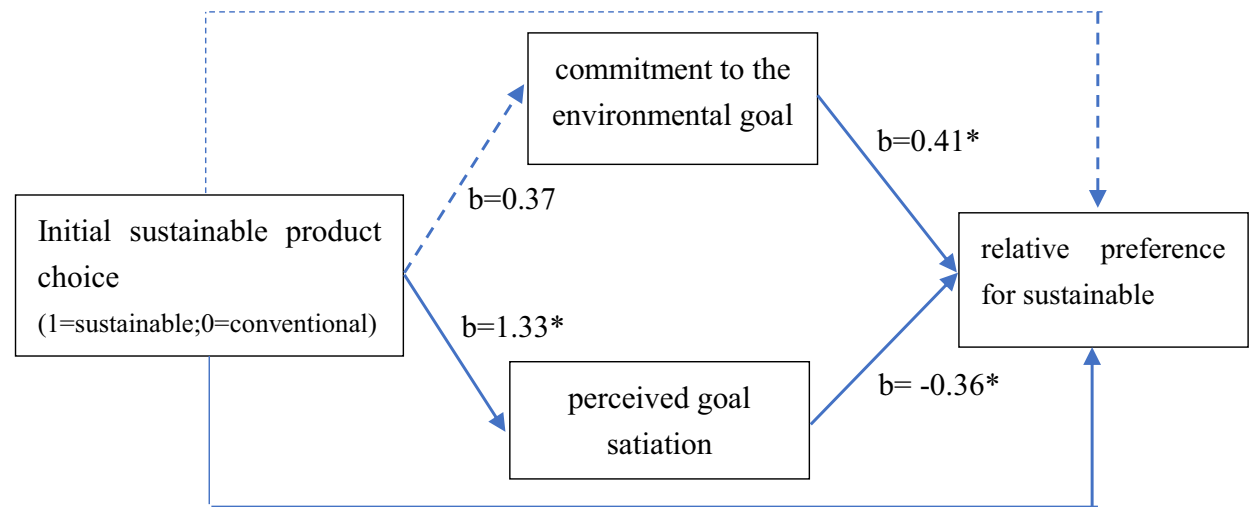

b

Indirect effect via perceived goal satiation $=-0.64^{*}, 95 \% \mathrm{CI}=(-1.35,-0.23)$ behaviors as goal satiation, then reduced subsequent preference for sustainable products. However, individuals with an interdependent self-construal take a goal commitment perspective, represent their initial pro-environmental behaviors as commitment to pro-environmental goal, then enhanced preference subsequent sustainable products. The latter detrimental effect raises an important question: How marketers to mitigate the licensing effect of initial environmental actions on subsequent actions?

\section{Study 3: The Moderating Role of Others' Pro-Environmental Behaviours}

In Study 3, we have two major goals. First, the primary purpose is to test an intervention by reminding others' pro-environmental behavior in the first decision. Second, we wanted to extend our inquiry by changing our manipulation method for initial pro-environmental behavior. In the first two studies, we manipulated initial pro-environmental behavior by a purchase decision between an eco-product and a traditional product. Study 3 assess robustness by using another pro-environmental manipulation method (Mazar \& Zhong, 2010).

\section{Method}

\section{Participants and Design}

207 undergraduates from three different universities in China (112 females and 95 males, $\mathrm{M}=21.47, \mathrm{SD}=2.77$ ) were randomly recruited to take part in this study. This study used a 2 (first decision: environmentally friendly purchase vs. conventional purchase) $\times 2$ (self-construal: independent vs. interdependent) $\times 3$ (others' pro-environmental behavior: high participation vs. low participation vs. information lack) experimental design. 


\section{Procedure}

The manipulation of self-construal priming was the same as study 1 and 2 . Then, we manipulated initial pro-environmental behavior using Mazar and Zhong's (2010) procedure. Participants in the pro-environmental purchase group were asked to make a shopping list that carried nine green products and three conventional products. The conventional purchase group were asked to choose from a store with nine traditional products and three green ones. The stores did not differ in number of products, product categories, or price, so choosing a greener alternative does not require self-sacrifices (see Appendix for details). We told participants to fill their baskets by choosing any number of each product with the budget constraint of $¥ 120$ (The price of each product is between $¥ 12$ and $¥ 30$ ). We encouraged them to choose as many products as possible.

In the next task, we manipulated others' pro-environmental behavior. In high participation of others' environmentally friendly purchase condition, participants received a message: "According to our previous survey result, $80 \%$ participants chose green products in the task that you just participated in". In low participation of others' environmentally friendly purchase condition, participants received a message: "According to our previous survey result, $20 \%$ participants chose green products in the task that you just participated in". In the information lack condition, participants were presented with no information.

We asked participants to demonstrate their preference for a sweater made from recycled versus traditional material as a measure for the second pro-environmental decision. Specially, participants first read short product descriptions of two sweaters. They were told that two sweaters were made from different materials, which came from recycled/ traditional cotton and polyester. Moreover, sweaters made from recycled materials were priced a third higher than traditional ones. Except for the difference in construction materials and price, there was no difference between these two sweaters. We asked participants to report their relative preference for the sweater from recycled material rather than conventional sweater using a 7-point scale $(1=$ most likely to purchase the sweater from traditional material and $7=$ most likely to purchase the sweater from recycled material).

Finally, participants then responded to psychological process measures including goal satiation, commitment to the environmental-friendly goal, manipulation check questions, as well as background information (e.g., gender, age).

\section{Results}

\section{Manipulation Checks}

We conducted a three-way ANOVAs, in which dependent variables were independent/interdependent self-construal manipulation check measures, and independent variables were environmental responsibility of the first decision, self-construal, and others' pro-environmental behavior. As we predicted, the results demonstrated that independent self-construal check measure was higher for independent self-construction group than interdependent self-construction group ( $M_{\text {independent self-construal }}=4.90$ vs $\mathrm{M}_{\text {interdependent self-construal }}=4.28 ; \mathrm{F}(1,357)=15.18, p$ $<.001)$. Interdependent self-construction group also reported higher on the interdependent self-construal items than independent self-construction group (M interdependent self-construal $=5.69, \mathrm{M}_{\text {independent self }}=5.03 ; \mathrm{F}(1$, $357)=30.33, p<.001)$. To check the validity of manipulation for the environmental responsibility of the first decision, we conducted another three-way ANOVAs with the environmental responsibility of the first decision measures as the dependent variables and environmental responsibility of the first decision, self-construal, and others' pro-environmental behavior as independent variables. According to the data analysis results, the environmentally friendly purchase group indicated more pro-environmental for the first decision than the control group $(\mathrm{F}(2,357)=$ $20.25, p<.001 ; \mathrm{M}_{\text {pro-environmental }}=4.45, \mathrm{M}_{\text {control }}=3.87$, $\left.\mathrm{p}_{\text {pro-environmental } / \text { control }}<.01\right)$.

\section{Hypotheses Testing}

An self-construal $\times$ first pro-environmental decision $\times$ others' pro-environmental behavior ANOVA on relative preference for sustainable products demonstrated the expected interaction $(\mathrm{F}(2,346)=5.59, p<.01)$. By testing the effect of high or low others' environmentally friendly purchase conditions, we confirm $\mathrm{H} 3$ and $\mathrm{H} 4$.

First examining independent self-construal group, the results of ANOVA revealed a significant interaction between others' environmentally friendly behavior and first decision $(\mathrm{F}(1,182)=8.50, p<.001)$. Consistent with H1, in lack of information on others' environmentally friendly behavior condition, individual with independent self-construal showed lower preference for the sweater from recycled material after choosing more green products than control group $\left(\mathrm{M}_{\text {pro-environmental }}=3.13 \mathrm{vs.} \mathrm{M}_{\text {control }}=3.89, \mathrm{t}(60)=\right.$ $2.14, p<0.05)$; in low participation of others' pro-environmentally behavior condition, individual with independent self-construal also showed lower preference for the sweater from recycled material after choosing more green convenience products in the first decision $\left(\mathrm{M}_{\text {pro-environmental }}=3.43\right.$ vs. $\left.\mathrm{M}_{\text {control }}=4.56, \mathrm{t}(63)=4.83, p<0.01\right)$. However, in high others' environmentally friendly behavior condition, the differences across two first decision conditions diminish (M pro-environmental $=4.28$ vs. $\left.\mathrm{M}_{\text {control }}=4.76, \mathrm{t}(63)=1.75, \mathrm{~ns}\right)$. To further examine the moderate role of others' environmentally friendly behavior, we compare the difference in 
relatively preference for the sweater from recycled material between initial green goods purchase and initial conventional goods purchase across three others' environmentally friendly behavior conditions. The results showed that those primed with an independent self-construal reported lower relatively preference for the sweater from recycled material after getting to know high participation of others' environmentally friendly behavior, compared with low participation of others' environmentally friendly purchase and information lack $(\Delta M$ no information $=-0.76, \Delta M$ low others $=-1.13, \Delta \mathrm{M}_{\text {high others }}=-0.48 ; \mathrm{p}_{\text {low others } / \text { control }}<0.05$, $\mathrm{d}=0.65 ; \mathrm{p}$ high others / control $=.07, \mathrm{~d}=0.54$; Fig. 4, Panel a). That is, the licensing effect of initial pro-environmental behaviors for those with independent self-construal will be weaker after reminding them high participation of others' pro-environmental behavior, while the licensing effect will be stronger after reminding them low participation of others' pro-environmental behavior.

Then Examine interdependent self-construal group, a two-way ANOVA showed the interaction between others' environmentally friendly behavior and first decision on relative preference for sustainable products also emerged
$(\mathrm{F}(1,184)=9.23, p<.001)$. The further analysis showed that those with an initial sustainable consumption choice reported higher preference for the sweater made from recycled material than participants with an initial conventional consumption when they knew high level of others' environmentally friendly behavior $\left(\mathrm{M}_{\text {pro-environmental }}=5.56 \mathrm{vs}\right.$. $\mathrm{M}$ control $=4.48, \mathrm{~F}(1,184)=3.40, p=.07)$. On the contrary, there was no different effect between an initial sustainable consumption choice and an initial conventional consumption when they knew the level of others' environmentally friendly behavior was low ( $\mathrm{M}_{\text {pro-environmental }}=4.37 \mathrm{vs.} \mathrm{M}$ control $=4.40, \mathrm{~F}(1,184)=1.63, p=0.20)$. In addition, in consistent with previous findings in study 1 and study 2 , when no information about others' environmentally friendly behavior, participants in initial sustainable (vs. conventional) consumption choice condition reported higher preference for the sweater made from recycled material (M pro-environmental $=4.40$ vs. $\mathrm{M}$ control $=3.67, \mathrm{~F}(1,184)=3.06$, $p=0.08)$. Moreover, interdependent self-construal group reported relatively higher preference for the sweater from recycled material after getting to know high participation of others' environmentally friendly behavior, compared with
Fig. 4 Graphical representation of Study 3 results

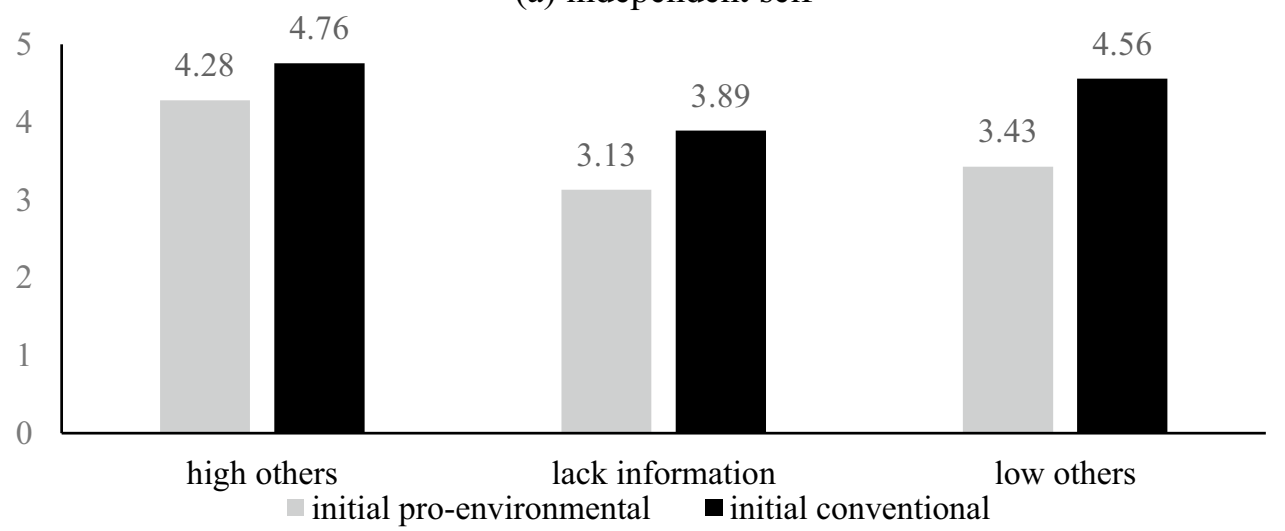

(b) independent self

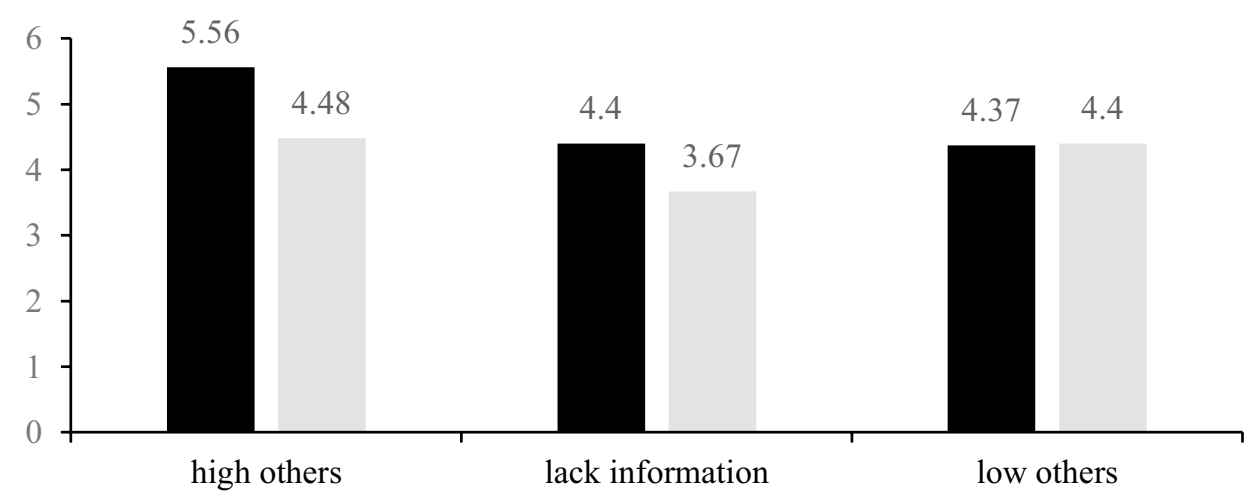

匹 initial pro-environmental initial conventional 
low level of others' environmentally friendly purchase and information lack $\left(\Delta \mathrm{M}_{\text {no information }}=0.73, \Delta \mathrm{M}_{\text {low others }}=-0.03\right.$, $\Delta \mathrm{M}_{\text {high others }}=1.08 ; \mathrm{p}_{\text {low others / }}$ control $<0.05, \mathrm{~d}=0.71 ; \mathrm{p}$ high others /control $=0.08, \mathrm{~d}=0.52 ;$ Fig. 4, Panel b). That is, for those with interdependent self, the self-consistency effect of initial pro-environmental behaviors will be stronger after reminding them high participation of others' pro-environmental behavior, while the self-consistency effect will be weaker after reminding them low participation of others' pro-environmental behavior.

\section{Discussion of Study 3}

The results of study 3 show the licensing effect of an initial pro-environmental behavior among participants with independent self-construal can be mitigated by emphasizing high (vs. low vs. no information) participation of others' pro-environmental behaviors, while consistency effect among participation with interdependent self-construal can be enhanced by emphasizing high (vs. low vs. no information) participation of others' pro-environmental. This finding not only provides support for $\mathrm{H} 3$ and $\mathrm{H} 4$, but also provides further indirect evidence for the underlying psychological mechanism of goal satiation. A number of studies have shown that people measure their progress according to the performance of others (Festinger, 1954). This tendency to compare oneself to others is so strong that it manifests itself spontaneously without explicit instructions (Gilbert et al., 1995). The more (less) other people engage in pro-environmental behavior, the less (more) an initial pro-environmental behavior can be viewed as progress on pro-environmental goal. Therefore, the findings that the licensing effect of an initial pro-environmental behavior among participants with accessible independent self-construal can be mitigated by emphasizing high (vs low or no information) participation of others' pro-environmental behaviors provides further evidence for the underlying psychological mechanism of goal satiation. This study also shows that marketers can take (and avoid) to encourage people to persistently engage in proenvironmental behaviors.

\section{General Discussion}

In this study, we examine the contingent role of self-construal in the effect of previous pro-environmental behavior on subsequent behavior. Previous literature in moral psychology has yielded two conflict predictions. On one hand, a previous pro-environmental behavior could increase people's pro-environmental self-perceptions and enhance subsequent environmental protection behavior. On the other hand, an initial pro-environmental behavior also may enhance goal satiation which will subsequently result in licensing effects that reduce intention to engage in subsequent proenvironmental behavior. With three experimental studies, we explored when and why consumers revealed a licensing effect or consistency effect in subsequent pro-environmental decisions after their initial pro-environmental behavior. Specially, we revealed that the effect of previous environmentally friendly behavior on subsequent pro-environmental behavior were contingent upon consumers' self-construal. Individuals with independent self-construal are more likely to represent original pro-environmental behavior as commitment to pro-environmental goal (i.e., pro-environmental self-perceptions) which thus reinforces future pro-environmentally behaviors (i.e., self-consistency effect). On the contrary, individuals with independent self-construal are more likely represent initial pro-environmental behavior as progress towards pro-environmental goal which then undermines future environmentally responsible behaviors (i.e., licensing effect) (Study 1). What's more, this shift in emphasis is driven by goal satiation for licensing effect and pro-social perceptions for self-consistency effect (Study 2). Furthermore, we identified the information about others' high level of pro-environmental behavior as an effective means to ease the effect of licensing upon consumers with independent self, and to enhance the self-consistency effect upon consumers with interdependent self-construal (Study 3 ). In conclusion, our research offers implications for policymaking department and marketing staff, and also make some theoretical contributions to several research areas.

\section{Theoretical Contributions}

This research has some theoretical contributions. First, this study enriches research on sustainable product consumption in a number of ways. Whereas prior research examining the effect of previous pro-environmental behavior on subsequent pro-environmental behavior has predominately focused upon the impact of previous sustainable product consumption on subsequent moral behavior in irrelevant fields, for instance, cheat or steal on a task (Mazar \& Zhong, 2010), the current study explore how to strengthen or break succedent sustainable consumption behaviors for sustainable-products over time. Our work reveals that both self-consistency and moral licensing mechanisms of past sustainable consumption simultaneously counterproductive in the decision-making process. Although these have been studied separately in the previous literature, the current research integrates them with research on self-construal and examines their common subsequent influence on sustainable consumption behavior. Given the mixed mechanisms, how past sustainable product consumption influence subsequent sustainable consumption decision is unclear. Our key contribution to sustainable consumption is to identity the contingent role of self-construal. 
Second, our research can conduce to the study of moral license literature by identifying the conditions under which licensing effects occur. Although some moderators, such as construal level (Conway \& Peetz, 2012), ambiguous initial behavior (Effron \& Monin, 2010), have been identified, we contribute to the literature by introducing self-construal as a new moderate variable. Given the strong association between self-construal and culture background, this study provides an explanation for Simbrunner and Schlegelmilch (2017) 's meta-analytical findings that moral license effect only occurs in North America and Western Europe, while moral licensing has the opposite effect in southeast Asia. As far as we know, we first focused on the contingent role of self-construal in moral licensing effect. Moreover, we affirm that a person with independent self-construal mind is inclined to interpret their previous consumption decisions as perceived progress toward the goal of being an environmentally concerned person which underlies the license effect.

Third, our research also can conduce to goal regulation theory (Fishbach et al., 2009) by highlighting the role of self-construal in determining when a previous goal related behavior is represented as commitment to the focal goal or progress towards the goal. The goal regulation theory argues that goal actions can be interpreted as progress or commitment towards an ideal goal state. If goal actions are represented in terms of commitment, previous goal actions should highlight this goal and enhance the incentive to select concerted actions later. Conversely, if goal actions are interpreted as progress, previous goal actions lead to the feeling that part of the goal has been achieved and reduces your efforts to achieve your goals (Fishbach \& Dhar, 2005; Fishbach \& Finkelstein, 2012; Fishbach et al., 2009). Although some variables that inferring from behavior whether it is affected by commitment or progress have been identified, such as pre-existing commitment certainty (Koo \& Fishbach, 2008), salient superordinate goal (Fishbach et al., 2006), presentation format (Fishbach \& Zhang, 2008), this study extends them by highlight the role of self-construal in determining whether to infer commitment or progress through behavior.

\section{Public Policy and Marketing Implications}

For policy makers and sustainability-oriented organizations, they need to figure out why people choose and how to handle products with environmental impacts. Our findings have important implications for understanding these questions. Our findings suggest that past sustainable-product choice can undermine subsequent sustainable-product purchase intentions among consumers with independent self-construal while enhancing subsequent sustainable-product purchase intentions among consumers with interdependent self. Hence, marketers can utilize marketing strategy to activate and influence consumers' self-construal for enhancing market sales of sustainable products. Prior research shows self-construal can be temporarily activated and will have effects consistent with those of chronically important selfconstrual (Aaker \& Lee, 2001; Hamilton \& Biehal, 2005). Marketers who wish to promote the ecological characteristics of products and use them as differentiation points can utilize product advertisements, labels to temporarily activate interdependent.

Second, this research also has certain implications for the public policy-making sector. Our results suggest that moral license effect is a major obstacle for driving sustainable consumption. To reduce (or utilize) the license in the case of sequential selection, responsible public policy makers not only need to activate and influence consumers' self-construal but also actively remind people others' widely green consumption behavior.

\section{Limitations and Further Research}

This study has certain limitations. First of all, this article focuses on behaviors that occur frequently but have little impact (such as household essentials purchase), but not on behaviors that occur infrequently but have a greater impact (such as installing solar panels). Although these behaviors are essentially the same, the larger and less influential behaviors can be very different in decision-making. Highimpact behaviors need to be taken seriously and consideration (Trudel, 2019), which will become an important research direction in this field in the future. Second, we manipulate sustainable-product choice by asking participants imagination for purchase behaviors rather than real purchase scenario. Future research is merited to make a field study to examine our results, which would conduce to expand the external validity of our study.

Funding The authors gratefully acknowledge financial support from the National Natural Science Foundation of China (NSFC) (Grant No. 72102086) and the Youth Innovative Talents Project of Department of Education of Guangdong Province (Grant No. 2018WQNCX185). This project is also partially supported by Research Institute on Brand Innovation and Development of Guangzhou (Grant No.12621976).

Data Availability The datasets generated during and/or analysed during the current study are available from the corresponding author on reasonable request.

\section{Declarations}

Ethical Approval All procedures performed in studies involving human participants were in accordance with the ethical standards of the institutional and/or national research committee and with the 1964 Helsinki declaration and its later amendments or comparable ethical standards. 
Informed Consent Informed consent was obtained from all individual participants included in the study.

Conflict of Interest The authors declare that they have no conflict of interest.

Open Access This article is licensed under a Creative Commons Attribution 4.0 International License, which permits use, sharing, adaptation, distribution and reproduction in any medium or format, as long as you give appropriate credit to the original author(s) and the source, provide a link to the Creative Commons licence, and indicate if changes were made. The images or other third party material in this article are included in the article's Creative Commons licence, unless indicated otherwise in a credit line to the material. If material is not included in the article's Creative Commons licence and your intended use is not permitted by statutory regulation or exceeds the permitted use, you will need to obtain permission directly from the copyright holder. To view a copy of this licence, visit http://creativecommons.org/licenses/by/4.0/.

\section{References}

Aaker, J. L., \& Lee, A. Y. (2001). "I" Seek Pleasures and "We" Avoid Pains: The Role of Self-Regulatory Goals in Information Processing and Persuasion. Journal of Consumer Research, 28(1), 33-49. https://doi.org/10.1086/321946

Antonetti, P., \& Maklan, S. (2014). Feelings that Make a Difference: How Guilt and Pride Convince Consumers of the Effectiveness of Sustainable Consumption Choices. Journal of Business Ethics, 124(1), 117-134. https://doi.org/10.1007/s10551-013-1841-9

Aquino, K., Freeman, D., Reed, A., Lim, V., \& Felps, W. (2009). Testing a Social-Cognitive Model of Moral Behavior: The Interactive Influence of Situations and Moral Identity Centrality. Journal of Personality and Social Psychology, 97(1), 123-141. https://doi. org/10.1037/a0015406

Brewer, M. B., \& Gardner, W. (1996). Who Is This" We"? Levels of Collective Identity and Self Representations. Journal of Personality and Social Psychology, 71(1), 83-93. https://doi.org/10.1037/ 0022-3514.71.1.83

Conway, P., \& Peetz, J. (2012). When Does Feeling Moral Actually Make You a Better Person? Conceptual Abstraction Moderates Whether Past Moral Deeds Motivate Consistency or Compensatory Behavior. Personality and Social Psychology Bulletin, 38(7), 907-919. https://doi.org/10.1177/0146167212442394

Cornelissen, G., Pandelaere, M., Warlop, L., \& Dewitte, S. (2008). Positive cueing: Promoting sustainable consumer behavior by cueing common environmental behaviors as environmental. International Journal of Research in Marketing, 25(1), 46-55. https://doi.org/ 10.1016/j.ijresmar.2007.06.002

Cross, S. E., Hardin, E. E., \& Gercek-Swing, B. (2010). The What, How, Why, and Where of Self-Construal. Personality and Social Psychology Review, 15(2), 142-179. https://doi.org/10.1177/ 1088868310373752

Dhar, R., \& Simonson, I. (1999). Making Complementary Choices in Consumption Episodes: Highlighting versus Balancing. Journal of Marketing Research, 36(1), 29-44. https://doi.org/10.1177/00222 4379903600103

Effron, D. A., \& Monin, B. (2010). Letting People Off the Hook: When Do Good Deeds Excuse Transgressions? Personality and social psychology bulletin, 36(12), 1618-1634. https://doi.org/10.1177/ 0146167210385922
Etkin, J., \& Ratner, R. K. (2012). The Dynamic Impact of Variety among Means on Motivation. Journal of Consumer Research, 38(6), 1076-1092. https://doi.org/10.1086/661229

Festinger, L. (1954). A theory of social comparison processes. Human Relations, 7(2), 117-140. https://doi.org/10.1177/0018726754 00700202

Festinger, L. (1957). A theory of cognitive dissonance (Vol. 2): Stanford University Press.

Fishbach, A., \& Dhar, R. (2005). Goals as Excuses or Guides: The Liberating Effect of Perceived Goal Progress on Choice. Journal of Consumer Research, 32(3), 370-377. https://doi.org/10.1086/ 497548

Fishbach, A., Dhar, R., \& Zhang, Y. (2006). Subgoals as Substitutes or Complements: The Role of Goal Accessibility. Journal of Personality and Social Psychology, 91(2), 232-242. https://doi.org/ 10.1037/0022-3514.91.2.232

Fishbach, A., \& Finkelstein, S. R. (2012). How feedback influences persistence, disengagement, and change in goal pursuit. Goaldirected behavior (pp. 203-230). Psychology Press.

Fishbach, A., \& Zhang, Y. (2008). Together or Apart: When Goals and Temptations Complement Versus Compete. Journal of Personality and Social Psychology, 94(4), 547-559. https://doi.org/10.1037/ 0022-3514.94.4.547

Fishbach, A., Zhang, Y., \& Koo, M. (2009). The dynamics of self-regulation. European Review of Social Psychology, 20(1), 315-344. https://doi.org/10.1080/10463280903275375

Garvey, A. M., \& Bolton, L. E. (2017). Eco-Product Choice Cuts Both Ways: How Proenvironmental Licensing versus Reinforcement is Contingent on Environmental Consciousness. Journal of Public Policy \& Marketing, 36(2), 284-298. https://doi.org/10.1509/ jppm.16.096

Gholamzadehmir, M., Sparks, P., \& Farsides, T. (2019). Moral licensing, moral cleansing and pro-environmental behaviour: The moderating role of pro-environmental attitudes. Journal of Environmental Psychology, 65, 101334. https://doi.org/10.1016/j.jenvp. 2019.101334

Gilbert, D. T., Giesler, R. B., \& Morris, K. A. (1995). When comparisons arise. Journal of Personality and Social Psychology, 69(2), 227-236. https://doi.org/10.1037/0022-3514.69.2.227

Gupta, S., \& Ogden, D. T. (2009). To buy or not to buy? A social dilemma perspective on green buying. Journal of Consumer Marketing, 26(6), 376-391. https://doi.org/10.1108/0736376091 0988201

Hamilton, R. W., \& Biehal, G. J. (2005). Achieving Your Goals or Protecting Their Future? The Effects of Self-View on Goals and Choices. Journal of Consumer Research, 32(2), 277-283. https:// doi.org/10.1086/432237

Hayes, A. F. (2017). Introduction to mediation, moderation, and conditional process analysis: A regression-based approach: Guilford Publications.

Heine, S., Lehman, D., Markus, H., \& Kitayama, S. (1999). Is There a Universal Need for Positive Self-Regard? Psychological Review, 106(4), 766-794. https://doi.org/10.1037/0033-295X.106.4.766

Hong, J., \& Chang, H. H. (2015). "I" Follow My Heart and "We" Rely on Reasons: The Impact of Self-Construal on Reliance on Feelings versus Reasons in Decision Making. Journal of Consumer Research, 41(6), 1392-1411. https://doi.org/10.1086/680082

Huang, S.-C. (2018). Social Information Avoidance: When, why, and how it is Costly in Goal Pursuit. Journal of Marketing Research, 55(3), 382-395. https://doi.org/10.1509/jmr.16.0268

Huang, S.-C., Broniarczyk, S. M., Zhang, Y., \& Beruchashvili, M. (2015). From Close to Distant: The Dynamics of Interpersonal Relationships in Shared Goal Pursuit. Journal of Consumer Research, 41(5), 1252-1266. https://doi.org/10.1086/678958

Huang, S.-C., Etkin, J., \& Jin, L. (2017). How winning changes motivation in multiphase competitions. Journal of Personality and 
Social Psychology, 112(6), 813-837. https://doi.org/10.1037/ pspa0000082

Huang, S.-C., Jin, L., \& Zhang, Y. (2017). Step by step: Sub-goals as a source of motivation. Organizational Behavior and Human Decision Processes, 141, 1-15. https://doi.org/10.1016/j.obhdp. 2017.05.001

Karmarkar, U. R., \& Bollinger, B. (2015). BYOB: How Bringing Your Own Shopping Bags Leads to Treating Yourself and the Environment. Journal of Marketing, 79(4), 1-15. https://doi.org/10.1509/ jm. 13.0228

Koo, M., \& Fishbach, A. (2008). Dynamics of self-regulation: How (un)accomplished goal actions affect motivation. Journal of Personality and Social Psychology, 94(2), 183-195. https://doi.org/ 10.1037/0022-3514.94.2.183

Krishna, A., Zhou, R., \& Zhang, S. (2008). The Effect of Self-Construal on Spatial Judgments. Journal of Consumer Research, 35(2), 337-348. https://doi.org/10.1086/588686

Lee, S., \& Pounders, K. R. (2019). Intrinsic versus extrinsic goals: The role of self-construal in understanding consumer response to goal framing in social marketing. Journal of Business Research, 94, 99-112. https://doi.org/10.1016/j.jbusres.2018.04.039

Markus, H. R., \& Kitayama, S. (1991). Culture and the Self: Implications for Cognition, Emotion, and Motivation. Psychological Review, 98(2), 224-253. https://doi.org/10.1037/0033-295X.98.2. 224

Mazar, N., \& Zhong, C.-B. (2010). Do Green Products Make Us Better People? Psychological Science, 21(4), 494-498. https://doi.org/ 10.1177/0956797610363538

Mullen, E., \& Monin, B. (2016). Consistency Versus Licensing Effects of Past Moral Behavior. Annual Review of Psychology, 67(1), 363-385. https://doi.org/10.1146/annurev-psych-010213-115120

$\mathrm{Ng}$, S., \& Houston, M. J. (2006). Exemplars or Beliefs? The Impact of Self-View on the Nature and Relative Influence of Brand Associations. Journal of Consumer Research, 32(4), 519-529. https://doi. org/10.1086/500482

Nielsen, K. S. (2017). From prediction to process: A self-regulation account of environmental behavior change. Journal of Environmental Psychology, 51, 189-198. https://doi.org/10.1016/j.jenvp. 2017.04.002

Noblet, C. L., \& McCoy, S. K. (2017). Does One Good Turn Deserve Another? Evidence of Domain-Specific Licensing in Energy Behavior. Environment and Behavior, 50(8), 839-863. https:// doi.org/10.1177/0013916517718022

Reczek, R. W., Trudel, R., \& White, K. (2018). Focusing on the forest or the trees: How abstract versus concrete construal level predicts responses to eco-friendly products. Journal of Environmental Psychology, 57, 87-98. https://doi.org/10.1016/j.jenvp.2018.06.003

Schwabe, M., Dose, D. B., \& Walsh, G. (2018). Every Saint has a Past, and Every Sinner has a Future: Influences of Regulatory Focus on Consumers' Moral Self-Regulation. Journal of Consumer Psychology, 28(2), 234-252. https://doi.org/10.1002/jcpy.1025

Shaddy, F., Fishbach, A., \& Simonson, I. (2021). Trade-Offs in Choice. Annual Review of Psychology, 72, 181-206. https://doi.org/10. 1146/annurev-psych-072420-125709

Simbrunner, P., \& Schlegelmilch, B. B. (2017). Moral licensing: a culture-moderated meta-analysis. Management Review Quarterly, 67(4), 201-225. https://doi.org/10.1007/s11301-017-0128-0

Singelis, T. M. (1994). The Measurement of Independent and Interdependent Self-Construals. Personality and social psychology bulletin, 20(5), 580-591. https://doi.org/10.1177/0146167294205014

Steinmetz, J., Xu, Q., Fishbach, A., \& Zhang, Y. (2016). Being observed magnifies action. Journal of Personality and Social Psychology, 111(6), 852-865. https://doi.org/10.1037/pspi0000065

Susewind, M., \& Hoelzl, E. (2014). A matter of perspective: why past moral behavior can sometimes encourage and other times discourage future moral striving. Journal of Applied Social Psychology, 44(3), 201-209. https://doi.org/10.1111/jasp.12214

Thøgersen, J. (2004). A cognitive dissonance interpretation of consistencies and inconsistencies in environmentally responsible behavior. Journal of Environmental Psychology, 24(1), 93-103. https:// doi.org/10.1016/S0272-4944(03)00039-2

Thøgersen, J., \& Crompton, T. (2009). Simple and Painless? The Limitations of Spillover in Environmental Campaigning. Journal of Consumer Policy, 32(2), 141-163. https://doi.org/10.1007/ s10603-009-9101-1

Trafimow, D., Triandis, H. C., \& Goto, S. G. (1991). Some tests of the distinction between the private self and the collective self. Journal of Personality and Social Psychology, 60(5), 649-655. https://doi. org/10.1037/0022-3514.60.5.649

Trudel, R. (2019). Sustainable consumer behavior. Consumer Psychology Review, 2(1), 85-96. https://doi.org/10.1002/arcp.1045

Urban, J., Bahník, Š, \& Kohlová, M. B. (2019). Green consumption does not make people cheat: Three attempts to replicate moral licensing effect due to pro-environmental behavior. Journal of Environmental Psychology, 63, 139-147. https://doi.org/10. 1016/j.jenvp.2019.01.011

van der Werff, E., Steg, L., \& Keizer, K. (2014). Follow the signal: When past pro-environmental actions signal who you are. Journal of Environmental Psychology, 40, 273-282. https://doi.org/ 10.1016/j.jenvp.2014.07.004

van Valkengoed, A. M., \& Steg, L. (2019). Meta-analyses of factors motivating climate change adaptation behaviour. Nature Climate Change, 9(2), 158-163. https://doi.org/10.1038/ s41558-018-0371-y

Wheeler, T., \& Von Braun, J. (2013). Climate change impacts on global food security. Science, 341(6145), 508-513.

White, K., Habib, R., \& Hardisty, D. J. (2019). How to SHIFT Consumer Behaviors to be More Sustainable: A Literature Review and Guiding Framework. Journal of Marketing, 83(3), 22-49. https:// doi.org/10.1177/0022242919825649

Yang, H., Stamatogiannakis, A., \& Chattopadhyay, A. (2015). Pursuing Attainment versus Maintenance Goals: The Interplay of SelfConstrual and Goal Type on Consumer Motivation. Journal of Consumer Research, 42(1), 93-108. https://doi.org/10.1093/jcr/ ucv008

Zhang, Y., \& Shrum, L. J. (2008). The Influence of Self-Construal on Impulsive Consumption. Journal of Consumer Research, 35(5), 838-850. https://doi.org/10.1086/593687

Zhu, R., \& Meyers-Levy, J. (2009). The Influence of Self-View on Context Effects: How Display Fixtures Can Affect Product Evaluations. Journal of Marketing Research, 46(1), 37-45. https://doi. org/10.1509/jmkr.46.1.37

Publisher's note Springer Nature remains neutral with regard to jurisdictional claims in published maps and institutional affiliations. 